CE ARTICLE

\title{
Uncovering the mask of borderline personality disorder: Knowledge to empower primary care providers
}

\author{
Hiba Wehbe-Alamah, PhD, RN, FNP-BC, CTN-A (Associate Professor) \& Susan Wolgamott, DNP, RN, CEN, CTN-B \\ (Lecturer)
}

Department of Nursing, School of Health Professions and Studies, University of Michigan-Flint, Flint, Michigan

\author{
Keywords \\ Content analysis; mental health; borderline \\ personality; internet blogs; research; \\ disparities.

\section{Correspondence \\ Hiba Wehbe-Alamah, PhD, RN, FNP-BC, CTN-A, Department of Nursing, School of Health Professions and Studies, University of Michigan-Flint, 303 East Kearsley Street, 2162 WSW, Flint, MI 48502-1950. \\ Tel: 810-766-6760; \\ Fax: 810-766-6851; \\ E-mail: hiba@umflint.edu} \\ Received: July 2013; \\ accepted: March 2014 \\ doi: 10.1002/2327-6924.12131 \\ To obtain CE credit for this activity, go to \\ www.aanp.org and click on the CE Center. \\ Locate the listing for this article and complete \\ the post-test. Follow the instructions to print \\ your CE certificate. \\ Disclosures
}

The authors report no competing interests.

\begin{abstract}
Purpose: This manuscript will provide a review of the literature and a report on the findings of a qualitative study that explored the lived experiences of people with borderline personality disorder (BPD). It also offers resources designed to empower healthcare professionals to provide timely and accurate referrals, diagnosis, or collaborative management of BPD in primary care.

Data sources: Review of the literature examining background, epidemiology, pharmacotherapy, psychotherapy, and available resources regarding BPD. Content analysis conducted on data obtained from 1109 postings on three different public online forums/blogs specifically for BPD.

Conclusions: BPD is characterized by unstable moods, behaviors, and relationships. While navigating a healthcare system fraught with health disparities, BPD sufferers may have their feelings of abandonment and hopelessness reinforced. Four core themes emerged (a) a reliance on online blogging to cope; (b) a quality of life that is impacted by debilitating effects of condition; (c) coping mechanisms that encompass healthy and destructive measures; and (d) social injustices that include stigmatization, prejudice, delayed diagnosis, misdiagnosis, limited healthcare access, and lack of cure.

Implications for practice: Knowledgeable, nonjudgmental primary healthcare providers can play a key role in providing BPD sufferers and their loved ones with accurate and timely diagnosis, referral, treatment, resources, and support. Internet blogging may have important implications in care.
\end{abstract}

Mental health disorders are the leading cause of disability in the United States and Canada and have a financial burden that is higher than diabetes, heart disease, and obesity (U.S. Department of Health and Human Services [DHHS], Healthy People 2020, 2012). Proper effective care has benefits that far outweigh the costs in overall quality of life and burden on the healthcare system. Recent mental healthcare reform policies, driven by the need to reduce healthcare disparities, have begun to address the disparities in care by providing benefits where there were none, including reducing the copays to those with insurance and increasing the number of allowed visits (U.S. DHHS, Healthy People 2020, 2013). This relief effort, however, may not reach those suffering from the debilitating effects of borderline personality disorder (BPD). It is estimated that $5-10$ million people in the United
States are diagnosed with BPD (Osborne \& McComish, 2006) and most of them have no insurance and are either unemployed or unemployable.

BPD is one of the most challenging mental health disorders to treat. Intense fear of abandonment, labile moods, impulsivity, and interpersonal/relationship issues that characterize BPD often extend to the patient-provider relationship further reinforcing fears of stigmatization and prejudice (Markham, 2003; Trull, Distel, \& Carpenter, 2010). This disorder, first described in 1938 by Adolf Stern (Oldham, 1991; Stern, 1938), affects 1\%-3\% of the general population in the United States, accounts for $10 \%$ of mental health clients seen in outpatient clinical settings and $15 \%-20 \%$ of those in inpatient settings (Nehls, 1999; Trull et al., 2010). A 2007 study by Grant et al. (2008) reported equal BPD prevalence among men and women, 
with women suffering from substantial mental and physical disability. In contrast, the DSM-IV-TR conveyed a 3:1 female to male gender ratio (Sansone \& Sansone, 201 la). More studies are needed to determine current prevalence of BPD.

\section{Literature review}

While the literature does not provide a conclusive etiology for BPD, a collection of possible factors behind BPD was cited. Psychological factors such as abuse, neglect and abandonment during formative years, traumatic brain injury, and some biogenetic components seem to have a recurrent role in those that are diagnosed with BPD (Carlat, 1998; Gunderson, 2013; Johnson et al., 1999; Sansone $\&$ Sansone, $2011 \mathrm{la}$ ). BPD is five times more likely to occur among first degree biological relatives (Gunderson, 2013).

According to the literature, there are several hallmarks for potentially identifying BPD including unstable, intense relationships, self-loathing or self-harm, labile moods, inappropriate anger, and paranoid dissociative behavior (Gross et al., 2002; Gunderson, 2013). Selfinjurious behaviors may be present in the form of cutting, sexual promiscuity, binge eating, blunt physical violence, or excessive risk taking (Joyce, Light, Rowe, Cloninger, $\delta$ Kennedy, 2010). They may also include gambling, selfmutilation, substance abuse, anorexia, and in some instances, suicidal behaviors (Gunderson, 2011 ; Joyce et al., 2010; Lamph, 2011; Raven, 2009). Referral to appropriate specialists is indicated for accurate diagnosis and management because above-described signs and symptoms may be associated with other mental health diagnoses.

Some red flags that may appear in an office visit that should alert a primary care provider (PCP) to possible diagnosis of BPD comprise a history of doctor shopping, legal suits against healthcare professionals, suicide attempts, several brief marriages or unsuccessful intimate relationships, an immediate idealization of the PCP as the most "wonderful doctor" in comparison to any previous practitioners, and most importantly, an excessive interest in the PCP's personal life as well as attempts to test or invade professional boundaries (Carlat, 1998; Gross et al., 2002; Sansone \& Sansone, 2010). It is important to note that BPD is often misdiagnosed or may take years to be accurately diagnosed (Fallon, 2003; U.S. DHHS, Healthy People 2020, 2012).

A delayed or misdiagnosis is often compounded by the comorbid presence of bipolar, anxiety, depression, obsessive compulsive, or other mental health disorders (Oldham, 1991). Familiarity with the traits of BPD can help guide the healthcare professional in diagnosing and treating this complex disorder (Sansone $\&$ Sansone,
Table 1 DSM 5 criteria for diagnosis of borderline personality disorder

Patient must meet in both categories:

Significant impairments in personality functioning

- Impairment in self-functioning (identity or self-direction)

- Impairment in interpersonal functioning (empathy or intimacy)

One or more pathological personality traits

- Negative affectivity (emotional lability, anxiousness, separation insecurity, depressivity), disinhibition (impulsivity, risk taking), antagonism (hostility)

- Trait(s) expressed are relatively stable across time and situations

- Trait(s) not related to developmental stage or sociocultural environment

- Trait(s) cannot be solely the result of drug abuse or a general medical condition

APA (2012), Sarkis (2011)

$2011 \mathrm{~b})$. Some of the differential diagnoses to consider when dealing with a person exhibiting the characteristics of BPD are schizophrenia, bipolar disorder/cyclothymia, attention deficit hyperactivity disorder (ADHD), reactive psychosis, depression, anxiety, atypical depression, organic personality syndrome, substance abuse, organic mental disorder, and other personality disorders such as paranoid, histrionic, narcissistic, antisocial, dependent, and self-defeating; (American Psychiatric Association [APA], 2001). New DSM 5 criteria (Table 1) for diagnosing BPD were released in May 2013 and replaced the old DSM IV criteria. These updated criteria have reorganized BPD characteristics and behaviors into two categories that must be met for a diagnosis to be provided (APA, 2013; Sarkis, 2011).

Treatment for BPD is dependent on a combination of factors including the establishment of a therapeutic structure, supportive environment, clinician's readiness to consult in the event of suicidal threats, and patient commitment to treatment (Forsyth, 2007; Goodman, Roiff, Oakes, \& Paris, 2012; Gunderson, 2011, 2013). Patient commitment to treatment is perhaps the most important as therapy can be very lengthy, intense, and may involve 2-3 hours of time commitment per week for many years (Bland, Tudor, \& Whitehouse, 2007; Gunderson, 2011). Medications prescribed for BPD often require a trial and error process, which necessitates patience and persistence until peak effect, tolerable, and effective outcomes are achieved. In addition, medications are often used in combination with different psychotherapies to maximize the benefit to patients (Bland et al., 2007; Gunderson, 2013).

Antidepressants, antipsychotics, mood stabilizers, antianxiety, and omega 3 fatty acid supplementation all play a role in the management of BPD (Stoffers et al., 2010). The choice of medications chosen is often aimed 
at treating the most life-limiting or dangerous symptoms, and is tailored or adjusted to address side effects or complications. For example, while aripiprazole is effective for treating depression, anxiety, and anger expression in both men and women, it has frequent side effects that include headache, insomnia, nausea, numbness, constipation, and anxiety (Nickel et al., 2006). On the other hand, topiramate, a popular, well-tolerated, and effective mood stabilizer in the treatment of BPD, is well liked by women for its side effect of weight loss (Epocrates, 2012; Stoffers et al., 2010). Furthermore, several small studies have supported the use of omega 3 fatty acids (ethyl-eicosapentaenoic acids) in treating depression, anger/rage, and mood shifting. It was found that these fatty acids may augment the effects of other psychiatric medications (New York University, Langone Medical Center, 2013).

Psychotherapy, often used in the treatment of symptoms and behaviors associated with BPD, focuses on three evidence-based cognitive behavioral therapies (CBTs): mentalization-based therapy (MBT); dialectical behavior therapy (DBT); and transference-focused psychotherapy. The concepts and techniques employed in these therapies are often combined with traditional talk therapy and general psychiatric management. MBT (Stoffers et al., 2012) is known for its effectiveness in the treatment of BPD patients. This therapy may be chosen when the crux of the patient's disorder is focused around their sense of self (Bateman \& Fonagy, 2010). DBT focuses on interpersonal skills. In DBT, the patient replaces maladaptive behaviors and patterns with effective coping and behavioral responses, which improve overall functioning (Osborne \& McComish, 2006; Stoffers et al., 2012). Transference-focused psychotherapy has a lower dropout rate and lower suicide rate compared to traditional psychiatric care. It focuses on the internalized experiences of dysfunctional early relationships and unraveling the source of the disorder. It decreases impulsivity, rage/anger, irritability, and verbal/physical violence, and is often used with male BPD sufferers (Doering et al., 2010; Stoffers et al., 2012). Traditional psychiatric management may include any of the previously described CBTs, traditional talk therapy, medication management, inpatient intensive care, and crisis intervention (Marziali, Monroe-Blum, \& McCleary, 1999; Stoffers et al., 2012).

Online support communities provide an additional venue for BPD sufferers, friends, families, and significant others, to learn about the disorder and identify resources for treatment. Such online communities offer public or private virtual forums where people can communicate in a safe environment about their experiences, concerns, educational material, and coping mechanisms (WehbeAlamah, Kornblau, Haderer, \& Erickson, 2012).

\section{Methodology}

Inductive content analysis was used for analyzing qualitative data obtained from three public virtual forums that were identified through a search of "borderline personality disorder" (Blog Top Sites-BPD, Borderline Blog, and $\mathrm{BPD}$ and Me). These blogs were designated for sufferers of BPD and their families, friends, and loved ones as a means to communicate, express, share information and stories, and vent and process personal experiences. All forums used were public in nature and did not require approved membership for access to posts. The University of Michigan-Flint Institutional Review Board (IRB) approved this study with an exempt status because it utilized data from public online forums. Following IRB review, data were collected over the course of 1 month from the three forums listed above. A total of $1109 \mathrm{blog}$ entries posted on the web between May 23, 2007 and September 2011 were subjected to content analysis by two researchers.

Content analysis is an effective qualitative research method that incorporates a systematic analysis of content-sensitive verbal and/or written messages as well as visual communications (Cole, 1988; Elo \& Kyngas, 2008). With content analysis, descriptors are analyzed for common patterns that are further abstracted into themes. Using content analysis to examine virtual data is documented in the literature (Jones $\&$ Alony, 2008; Klem, Reppert, \& Visich, 1998; Lasker, Sogolow, \& Sharim, 2005; Sanders, Rogers, Gardner, \& Kennedy 2011 ; Seale, Charteris-Black, MacFarlane, \& McPherson, 2010; Wehbe-Alamah et al., 2012). For this study, the authors conducted independent data analysis of descriptors and identified common patterns. These patterns were later compared by both authors for confirmation and further abstraction into themes.

\section{Findings}

Four major themes emerged from the content analysis of the 1109 blog postings. Each theme is presented below with its representing patterns and descriptors (quotations):

Theme 1: Online blogging provides an outlet to seek and/or provide support and education, a means of coping with condition, and a venue for offering hope and a sense of normalcy.

Public forums dedicated to BPD provide a venue for all interested in learning about BPD, including individuals with BPD and those who care for someone with this condition. Content analysis revealed that BPD sufferers use online blogging to voice out their concerns, and to seek and provide support for others. Support was offered 
in the form of hopeful messages, resources, educational material, and sharing of personal stories and experiences with BPD, provided a sense of purpose, and enhanced perceived self-worth. Reading and responding to blogs and postings describing daily struggles with BPD helped individuals to realize that they are not alone, that there are others who experience similar emotional patterns and events, and helped to establish a sense of normalcy. Three patterns supported this theme:

Pattern 1: Online blogging provides a medium for seeking and providing support to self and others by sharing resources, educational material, and accounts of daily experiences with BPD. Individuals living with BPD rely on the internet to learn about the condition. They find support in BPD blogs in terms of educational and other resources, sharing of personal experiences, and tips from other BPD sufferers. This was evidenced by a blogger who stated: “The reason I sat and read all of this is because I am looking for an answer to why somebody with BPD I loved very much walked out on me ... To read about this from the mind of somebody who has BPD ... has given me so much more than anything else I have read." Another blogger shared: "In addition to sharing my own experiences with BPD I have spent a lot of time reading others experiences, books and websites about the condition. All this research has resulted in a number of highly successful blog post that I hope inspire others and provide a good source of information and understanding about the condition."

Pattern 2: BPD sufferers use blogging as a coping mechanism and a form of therapy. Barriers in access to professional care/therapies have made blogging a viable option for many patients. Many BPD sufferers reported that they use online blogging as means of self-protection and healing. One blogger shared: "My writing is probably the best form of therapy at the moment as it is allowing me space to get my thoughts and feelings 'out' rather than burying them, but rather than talking, writing allows me more time to process my thoughts and make them coherent." Another blogger stated: "I am experimenting with distraction strategies when I feel like I want to self-harm and one of them involves keeping this blog which seems to be helping."

Pattern 3: Sharing of personal stories, encouraging messages, and reflections through blogging establishes a sense of normalcy and infuses a sense of hope for BPD sufferers. BPD sufferers derive hope from reading postings of other individuals living with BPD. Such hope stems from the realization that they are not alone, and that there are others out there who experience the turmoil associated with their condition. In addition, getting a glimpse of what other bloggers share about their experiences offers BPD sufferers a sense of normalcy and a support system that they can relate to and that can understand them for who they really are.
This was evidenced by three bloggers who shared: "For me, a lot of that hope comes from bloggers like you, because I can relate to your stories on so many levels and finally feel like someone 'gets' it," "We are ok right now as are, not defective," and "Don't give up on yourself if you have BPD. Yes it is destructive and dangerous, but that doesn't mean that's all we are. Truly there are other parts of us worth bringing out and living for."

Theme 2: The quality of life of people with BPD is impacted by the debilitating effect of the condition on emotional, physical, and mental health, the ability to maintain relationships, and the capability to function as a productive member of society.

When left untreated, BPD may turn over time into a painful and incapacitating disorder affecting every aspect of life and most of basic activities of daily living. Emotional, physical, and mental health symptoms reveal, identify, and point to the potentially devastating effects of the condition, including but not limited to the ability to seek or maintain employment and/or healthy long-term relationships. Four patterns supported this theme:

Pattern 1: People with BPD experience intense volatile emotions stemming from or leading to feelings of worthlessness, fear of abandonment, anger, rage, emptiness, guilt, despair, pain, recklessness, impulsivity, helplessness, hopelessness, and a desire to self-harm. BPD sufferers live with a range of strong and sometimes unstable/impulsive emotions on a daily basis. For a person living with BPD, fear of abandonment is either the cause or result of feelings of emptiness, despair, and pain: "I act like a desperate person because I AM desperate. I fear abandonment more than anything else ... DPT is the condition of a lost, deeply hurt soul ..." Other emotions reported by BPD sufferers include rage, anger, recklessness, impulsivity, helplessness, hopelessness, and a desire to harm: "It's as if a rabid feeling of rage comes over me and I lash out at the nearest person. ... It just happens because I feel so empty inside" and "at times I feel hopeless and worthless with no purpose and meaning in life due to this." BPD sufferers often experience remorse and regret over explosive and/or uncontrollable emotional outbursts: "After those 'attacks' I feel extremely guilty and I hate myself for hurting the people that mean a world to me."

Pattern 2: BPD effects on mental and physical health are manifested through bouts of anxiety, paranoia, delusions, depression, altered sleep cycles, lack of energy, and other symptoms. Many BPD sufferers described physical and mental manifestations of their condition that affected their ability to function as a productive member of society. Some BPD bloggers shared: "The impending fear of doom and overwhelming anxiety [about going back to work] building up to going is making me ill ... I felt nauseous 
just thinking about it $\ldots$ and had to rush to the toilet"; "Even short term separations trigger anxiety, stress, and paranoia"; "Intense feelings of sadness, loss and fear wreak havoc with your mind"; "It's a living hell"; "Is my BPD/Depression hindering my energy level, causing me to sleep all the time"?

Pattern 3: BPD sufferers struggle to maintain long-term relationships and recognize effect of condition on family and friends. People with BPD often have difficulty maintaining durable relationships. The myriad of labile emotions characterizing BPD is reported by some bloggers as a potential reason behind the inability to retain long-lasting relationships. A BPD sufferer shared: “My intimate relationships ... have a ... history of great moments and horrible disasters which I cannot explain ..." Another blogger stated: "I recently had BPD rage directed at me (non-BPD) and I ran like hell ... Now I hope she (BPD sufferer) just goes into a hole and rots." Interestingly, BPD sufferers also reported being aware of their condition's impact on family, friends, and significant others: “I do not discount the trauma they (non-BPD) may have been through, I have said on this very blog that I feel the family and friends of BPD sufferers are just as much victims in this as we (BPD sufferers) are ..."; and "as someone diagnosed with BPD, ... I see myself as a destructive force in occasional moments of clarity. I am manipulative, short tempered, moody, violent, and extremely difficult to live with... constantly draining the emotional reserves of other people in order to feel 'ok' ... I don't mean to do it ..."

Pattern 4: BPD sufferers struggle to maintain a career and conduct simple everyday life activities. The blogs reviewed for this study were rich with descriptors highlighting the incapacitating effects of BPD on everyday activities and on their ability to become employable. Many BPD bloggers shared their struggles: "I suffer from BPD. It is an extremely painful condition and gets in the way of every aspect of my life"; "People who are otherwise highly competent and bright find ordinary tasks difficult ..."; and "I don't have a job, cannot work and sometimes have trouble looking after even simple household chores."

Theme 3: People with BPD engage in healthy and destructive ways of coping with their condition.

In their quest to address the emotional, mental, and other repercussions associated with living with BPD, bloggers revealed an array of healthy coping mechanisms. Examples shared included (a) seeking professional psychotherapy when possible; a process that was often hindered by lack of accessibility, availability, and/or financial resources; (b) journaling, manifested in the form of blogging, which provided a medium for engaging in self-analysis and introspection; and (c) sharing successful creative self-help techniques, such as tips, manuals, and diverse resources. On the other hand, bloggers revealed that people with BPD may also engage in unintentional or uncontrollable destructive behaviors as a means of coping with their condition. These include but are not limited to cutting, binging, gambling, stalking, and engaging in acts of suicidal ideations or attempts, escapism, sexual promiscuity, recklessness, or impulsivity. Two patterns and their accompanying descriptors illustrated this theme:

Pattern 1: Healthy coping mechanisms used by people with $B P D$ include but are not limited to seeking professional psychotherapy, blogging, and sharing creative self-help techniques. BPD sufferers described using different effective psychotherapy techniques and services such as Mindfulness Meditation Training and DBT: "Mindfulness meditation training can help people with BPD to feel less 'stuck' in their emotions, and less judgmental of the emotions and themselves" and "I've come a long way from my pre-DBT time when I thought the grocery store clerk could tell just by looking at me that I was 'crazy'." In addition, individuals with BPD used blogging to share personal tips and experience-based recommendations for others living with the condition as a means of support and empowerment: "I'd like to offer a short list of ways to maximize your time with a therapist that you may see infrequently or annually like me."

Pattern 2: Harmful coping mechanisms used by people with $B P D$ include engaging in escapism, as well as self-injurious, reckless, abusive, impulsive, and even fatal behaviors. Several BPD bloggers described engaging in practices that are potentially harmful to oneself or others in response to or as a result of their condition. Examples included stalking or obsessing over others, cutting oneself, thinking about committing suicide, binging, and altering independently the dose or combination of (occasionally self-prescribed) medications. Descriptors supporting this finding included: "I'm still at a loss for finding ways to get past sexual frustrations aside from stalking, following, or obsessing over women [to cope with sexual rejection]"; "When I cut myself or suggest suicide, I'm not doing it to seek attention or upset others: I am doing it as a cry for help because I know no other way of expressing my pain"; "The cocktail of medications I am on seems to be helping"; and "I am thinking that I need to get a handle on this urge to binge." Other coping mechanisms shared by BPD bloggers that may delay appropriate treatment included escapism strategies: “... daydreaming, disassociating, sleeping ... I have built up these patterns on escapism behaviors and find I need to surrender to these states to relieve stress ..."

Theme 4: People with BPD experience social injustices in the form of stigmatization and prejudice, delayed diagnosis and 
misdiagnosis, limited access to care and/or qualified healthcare providers (HCPS), and lack of a cure.

Bloggers reported experiencing disparities in health care when seeking mental health services such as misdiagnosis, delayed diagnosis, and lack of availability of qualified HCPs, resources, and cure. They also conveyed facing prejudice and stereotyping from the public as well as the healthcare team caring for them. Four patterns and their descriptors supported this theme:

Pattern 1: People with BPD report experiencing prejudice and stigmatization from the general public and from HCPs. BPD bloggers described facing stigmatization and prejudice both from society and healthcare professionals. They relate the stigma associated with their condition to an overall lack of knowledge of the condition: "When she (HCP) put borderline down as 'exploratory' diagnosis ... [I] asked her to remove it ... because I knew of the HUGE amount of stigma associated with borderline ... You wouldn't believe how many THERAPISTS speak so disparagingly about 'borderlines' \& say how they try to avoid having them as clients," and "I was horrified when I heard on the news just now about this story. I believe it could have horrible repercussions and increasing the stigma for people that have personality disorders and take medication."

Pattern 2: People with BPD report experiencing misinformation, misdiagnosis, and/or delayed diagnosis. In their quest to obtain an accurate and timely diagnosis of their condition, BPD sufferers often encounter many obstacles: "There is far too much misinformation on the internet without those who should know better adding to it"; "I wish I'd had this and the official diagnosis back then. It could have made the subsequent twenty years a lot different"; and "I suffered from BPD for the last 20 or so yearsthough it was misdiagnosed as depression."

Pattern 3: People with BPD report lack of unbiased and qualified HCPs as well as insurance coverage as barriers to healthcare access. BPD sufferers seeking appropriate treatment for their condition are often hindered by lack of access to expert HCPs and specialists who are able to facilitate early and accurate diagnosis and treatment. In addition, limited or no insurance coverage poses additional barriers to access to care. This pattern was supported by bloggers who stated: "A lack of understanding coupled with ... attitude of some professionals mean it can be hard for those of us with BPD to get access to the help and support we need" and "... so long as they can get access to treatment, which is still the biggest barrier for most BPD sufferers."

Pattern 4: People with BPD report being desperate for a cure. BPD sufferers conveyed a profound desperation and desire for a cure. Some bloggers shared: "Given a chance the majority of people with $\mathrm{BPD}$ are willing to try $A N Y$ -
THING to get better" and "... after all I still have no idea 'if' or 'when' any therapy/help for my BPD will actually materialize."

It is important to note that the study findings shared in this manuscript do not necessarily apply to every person living with BPD. HCPs need to conduct their own assessment but may incorporate knowledge gained from this article to assist them in this process.

\section{Discussion}

BPD is a chronic mental health condition that may be undiagnosed or misdiagnosed for years before it is uncovered and appropriately addressed. Unless properly diagnosed and treated, it could potentially lead to devastating and life-limiting outcomes. Bloggers utilized the virtual forums as a place where it was safe to share their angst, and vent their fears, helplessness, and frustrations among those who empathize and can offer solace. Their voice of despair was clearly conveyed in the content analysis of the blog posts. Findings from this study revealed that BPD sufferers want to be heard and not judged, and supported without being stigmatized. BPD was described as a condition that may affect one's ability to perform simple everyday activities, maintain healthy stable relationships, and/or function as a productive member of society.

These findings are supported by the literature. Fallon (2003) maintained that living with a BPD label, selfdestructive behavior, and limited access to care are important issues BPD sufferers have to deal with on an ongoing basis. Individuals with BPD may experience emotional instability, rage, and interpersonal relationship issues that could render them psychologically disabled and/or unable to keep a job (U.S. DHHS Healthy People 2020, 2012). Many people who live with BPD are either underemployed, unemployable, uninsured, or struggle to qualify for disability benefits. Medications and psychotherapies such as DBT are expensive even when there is insurance coverage because of associated copays (Lamph, 2011). This level of poverty has met with limited relief in the way of federal support for BPD patients (World Health Organization, 2010).

\section{Implications for practice}

PCPs including advance practice nurses have a crucial role to play in advocating for people with BPD. Figure 1 highlights authors' suggested keys to successfully care for people with BPD. Accordingly, knowledge and awareness of BPD diagnostic criteria, signs and symptoms, coupled with an unbiased attitude, form the basis for early and timely referral for appropriate diagnosis. Healthcare 


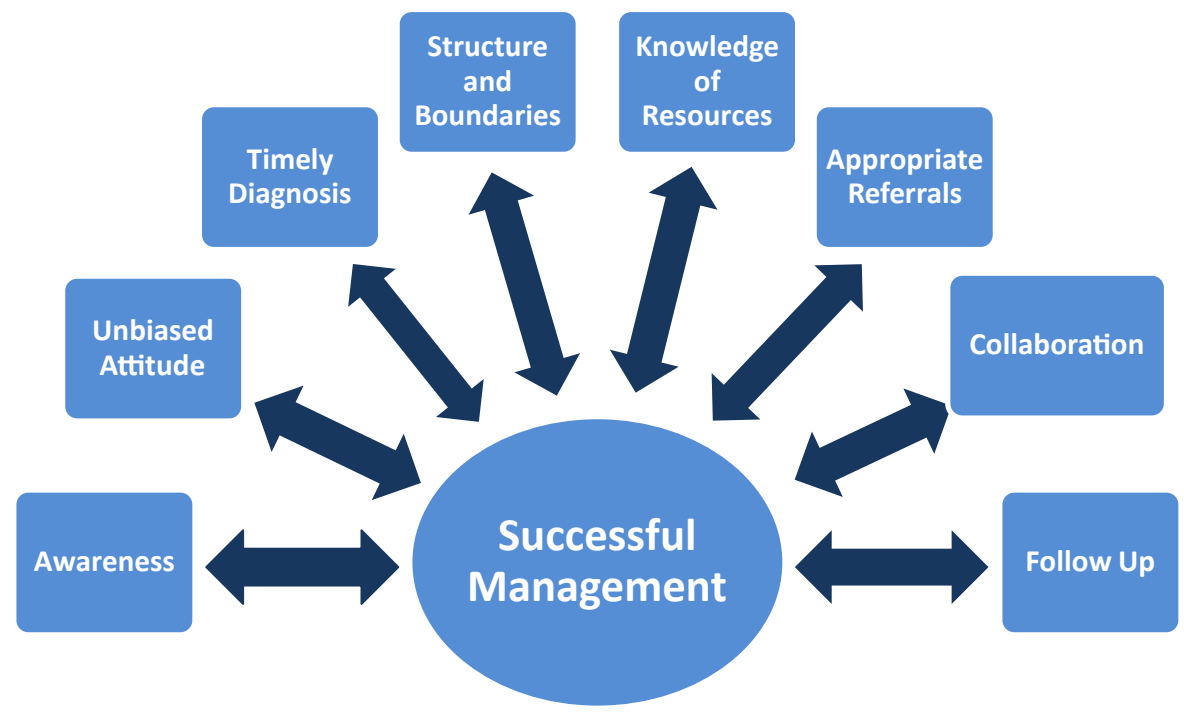

Figure 1 Keys to successful BPD management.

workers who lack compassion and tolerance and/or exhibit judgmental attitudes when dealing with demanding complex patients may validate the sense of abandonment and lack of trust experienced by BPD patients (Holm, Begat, \& Severinsson, 2009; Raven, 2009). Lack of understanding about BPD may lead to stigmatization and exclusion of services (Lamph, 2011).

Establishing necessary structure and boundaries for communicating may help prevent potential future conflicts and establish clear guidelines for what constitutes a therapeutic client-provider relationship. Comprehensive treatment is facilitated by initiation of appropriate referrals, follow-up (O'Brien, 1998; Osborne \& McComish, 2006), and interprofessional collaboration. This process is facilitated through the identification of accessible and affordable local and national resources. In addition to all of the above, HCPs can advocate for BPD by lobbying for additional legislature, research, policy, new treatment protocols, and insurance coverage (O'Brien, 1998; Osborne \& McComish, 2006).

A simple tool for use in the primary care setting, the I DESPAIRR mnemonic (Figure 2), highlights the hallmarks and red flags that identify a person as potentially having BPD (Carlat, 1998). Advanced practice nurses may use this tool to identify needs for appropriate referrals. Figure 3 provides additional resources for PCPs caring for people with BPD.

Many people are presenting to their PCPs for their mental healthcare needs. As patient advocates, advanced practice nurses should be prepared to care for people with BPD including engaging in crisis and symptom management, referrals to other HCPs, and identification and

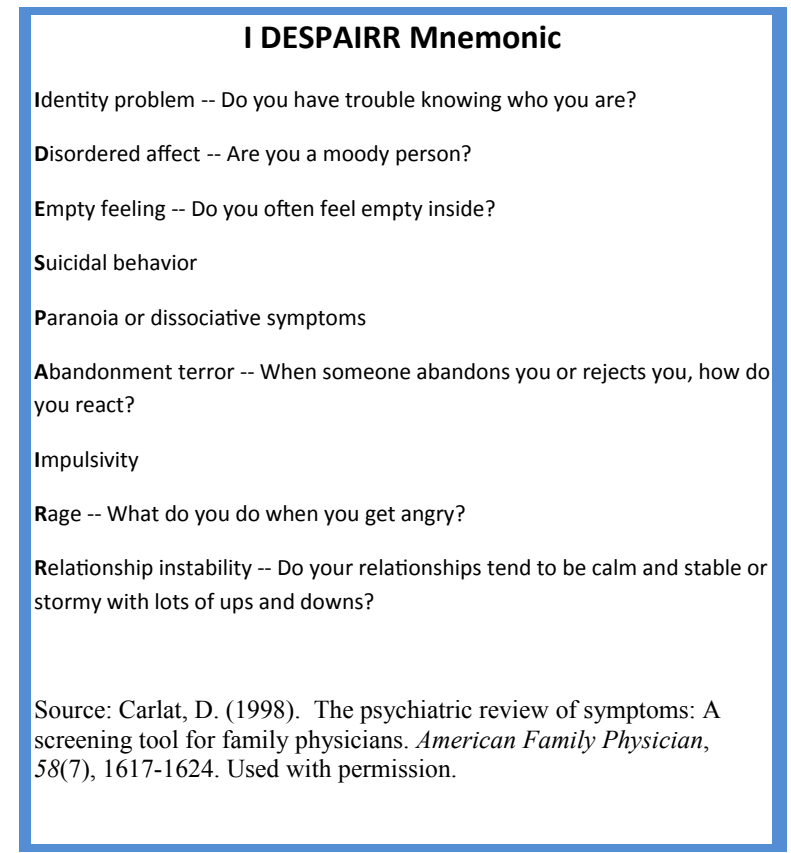

Figure 2 I DESPAIRR mnemonic.

sharing of resources such as CBT. Equipping oneself with the knowledge needed to accurately identify those who need referrals for appropriate diagnosis and management is an important prerequisite to delivering care that is congruent with the standards of the nursing profession. As an integral part of the interprofessional healthcare team, unbiased, knowledgeable, and compassionate advanced 


\begin{tabular}{|c|c|}
\hline General Information & $\begin{array}{l}\text { National Institute of Mental Health (NIMH) } \\
\text { http://www.nimh.nih.gov/health/topics/borderline-personality- } \\
\text { disorder/index.shtml } \\
\text { Substance Abuse and Mental Health Services Administration (SAMHSA) } \\
\text { http://www.samhsa.gov/ } \\
\text { Medline Plus (great patient handouts) } \\
\text { http://www.nlm.nih.gov/medlineplus/personalitydisorders.html } \\
\text { National Education Alliance for Borderline Personality Disorder } \\
\text { (NEA.BPD) } \\
\text { Rye, NY 10580 } \\
\text { (914) 835-9011 } \\
\text { www.borderlinepersonalitydisorder.com } \\
\text { neabpd@aol.com }\end{array}$ \\
\hline Current Research & $\begin{array}{l}\text { National Institute of Mental Health (NIMH) } \\
\text { http://www.nimh.nih.gov/topics/topic-page-borderline-personality- } \\
\text { disorder.shtml }\end{array}$ \\
\hline Healthcare Reform & http://www.samhsa.gov/healthReform/ \\
\hline Courses \& Training & $\begin{array}{l}\text { NEABPD CFamily Connections } \\
\text { 12-week course for relatives that provide education, coping skill } \\
\text { strategies, and support } \\
\text { (914) 835-9011 } \\
\text { www.borderlinepersonalitydisorder.com } \\
\text { info@neabpd.org } \\
\text { RESOURCES Behavioral Technology LLC } \\
\text { DBT referral, training and resources } \\
\text { 4556 University Way NE, Suite } 200 \\
\text { Seattle, Washington, 98105 } \\
\text { (206) 675-8588 } \\
\text { www.behavioraltech.com } \\
\text { information@behavioraltech.org }\end{array}$ \\
\hline Provider Directories & $\begin{array}{l}\text { BEHAVIORAL Tech, LLC } \\
\text { DBT Resources: Clinical Resource Directory } \\
\text { Listing of all registered DBT facilities/providers by State } \\
\text { http://behavioraltech.org/resources/crd.cfm } \\
\text { Psychology Today } \\
\text { The Therapy Directory } \\
\text { Listing of all registered Cognitive Behavioral Therapists by Zip Code } \\
\text { http://therapists.psychologytoday.com/rms/prof_search.php }\end{array}$ \\
\hline
\end{tabular}

Figure 3 Resources for primary care providers.

practice nurses are potent advocates to hearing and supporting the voices of those suffering with BPD.

\section{Acknowledgment}

The authors would like to acknowledge JoAnn Haderer, RN, DNP, for her assistance with the preliminary review of the literature on BPD.

\section{References}

American Psychiatric Association (APA). (2001). Guideline on treatment of patients with borderline personality disorder. American Journal of Psychiatry, 158(10 Suppl), 1-52.
American Psychiatric Association (APA). (2012). DSM-IV and DSM-5 criteria for the personality disorders. Retrieved from http://www.dsm5.org/Documents/ Personality\%20Disorders/DSM-IV\%20and\%20DSM-5\%20Criteria\% 20for $\% 20$ the $\% 20$ Personality \%20Disorders $\% 205-1-12$.pdf.

American Psychiatric Association (APA). (2013). DSM-5 development. Retrieved from http://www.dsm5.org/Pages/Default.aspx.

Bateman, A., \& Fonagy, P. (2010). Mentalization-based treatment for borderline personality disorder. World Psychiatry, 9(1), 11-15.

Bland, A., Tudor, G., \& Whitehouse, D. M. (2007). Nursing care of inpatients with borderline personality disorder. Perspectives in Psychiatric Care, 43(4), 204-212.

Carlat, D. (1998). The psychiatric review of symptoms: A screening tool for family physicians. American Family Physician, 58(7), 1617-1624.

Cole, L. (1988). Content analysis: Process and application. Clinical Nurse Specialist, 2(1), 53-57.

Doering, S., Horz, S., Rentrop, M., Fischer-Kern, M., Schuster, P., Benecke, C., ... Buchheim, P.(2010). Transference-focused psychotherapy v. 
treatment by community psychotherapists for borderline personality disorder: Randomised controlled trial. British Journal of Psychiatry, 196, 389-395. doi: 10.1192/bjp.bp.109.070177

Elo, S., \& Kyngas, H. (2008). The qualitative content analysis process. Journal of Advanced Nursing, 62 (1), 107-115.

Epocrates. (2012). In Epocrates Essentials for Android (Version 5.1) [Mobile application software]. Retrieved from http://www.epocrates.com/mobile/ android/essentials.

Fallon, P. (2003). Travelling through the system: The lived experience of people with borderline personality disorder in contact with psychiatric services. Journal of Psychiatric and Mental Health Nursing, 10(4), $393-400$.

Forsyth, A. (2007). Effects of diagnosis and non-compliance attributions on therapeutic alliance processes in adult acute psychiatric settings. Journal of Psychiatric and Mental Health Nursing, 14(1), 33-40.

Goodman, M., Roiff, T., Oakes, A., \& Paris, J. (2012). Suicidal risks and management in borderline personality disorder. Current Psychiatry Report, 14(1), 79-85. doi: 10.1007/s11920-011-0249-4

Grant, B., Chou, S., Goldstein, R., Huang, B., Stinson, F., Saha, T., \& Ruan, W. (2008). Prevalence, correlates, disability, and comorbidity of DSM-IV borderline personality disorder: Results from the wave 2 national epidemiologic Survey on alcohol and related conditions. Journal of Clinical Psychiatry, 69(4), 533-545.

Gross, R., Olfson, M., Gameroff, M., Shea, S., Feder, A., Fuentes, M., ... Weissman, M. (2002). Borderline personality disorder in primary care. Archives of Internal Medicine, 162, 53-60.

Gunderson, J. (2011). Borderline personality disorder. The New England Journal of Medicine, 364(21), 2037-2042.

Gunderson, J. (2013). An introduction to borderline personality disorder: A BPD brief. Retrieved from http://www.borderlinepersonalitydisorder.com/ professionals/a-bpd-brief/.

Holm, A. L., Begat, I., \& Severinsson, E. (2009). Emotional pain: Surviving mental health problems related to childhood experiences. Journal of Psychiatric and Mental Health Nursing, 16(7), 636-645.

Johnson, J., Cohen, P., Brown, J., Smailes, E., \& Bernstein, D. (1999). Childhood maltreatment increases risk for personality disorders during early adulthood. Archives of General Psychiatry, 56(7), 600-606.

Jones, M., \& Alony, I. (2008). Blogs-The new source of data analysis. Issues in Informing Science o Information Technology, 5(Annual), 433-446.

Joyce, P. R., Light, K. J., Rowe, S. L., Cloninger, R. C., \& Kennedy, M. A. (2010). Self-mutilation and suicide attempts: Relationships to bipolar disorder, borderline personality disorder, temperament, and character. Australian and New Zealand Journal of Psychiatry, 44(3), 250-257.

Klem, P., Reppert, K., \& Visich, L. (1998). A nontraditional cancer support group: The internet. Computers in Nursing, 16(1), 33-36.

Lamph, G. (2011). Raising awareness of borderline personality disorder and self-injury. Nursing Standard, 26(5), 35-40.

Lasker, J., Sogolow, E., \& Sharim, R. (2005). The role of an online community for people with a rare disease: Content analysis of messages posted on a primary biliary cirrhosis mailinglist. Journal of Medical Internet Research, 7(1), e10. Retrieved from http://www.ncbi.nlm.nih.gov/pmc/articles/ PMC1550634/?report=printable.

Markham, D. (2003). Attitudes towards patients with a diagnosis of borderline personality disorder: Social rejection and dangerousness. Journal of Mental Health, 12(6), 595-612.

Marziali, E., Munroe-Blum, H., \& McCleary, L. (1999). Effects of the therapeutic alliance on the outcomes of individual and group psychotherapy with borderline personality disorder. Psychotherapy Research, $9(4), 424-436$.

Nehls, N. (1999). Borderline personality disorder: The voice of patients. Research in Nursing $\theta$ Health, 22(4), 285-293.
New York University, Langone Medical Center. (2013). Fish oil. EBSCO Publishing. Retrieved from http://www.med.nyu.edu/content?ChunkIID= 21684\#

Nickel, M., Muehlbacher, M., Nickel, C., Kettler, C., Pedrosa-Gil, F., Bachler, E., ... Kaplan, P. (2006). Aripiprazole in the treatment of patients with borderline personality disorder: A double-blind, placebo-controlled study. American Journal of Psychiatry, 163(5), 833-838.

O'Brien, L. (1998). Inpatient nursing care of patients with borderline personality disorder: A review of the literature [Feature article]. Australian and New Zealand Journal of Mental Health Nursing, 7(4), 172-173.

Oldham, J. (1991). Borderline personality disorder: An introduction. Hospital and Community Psychiatry, 42(10), 1014.

Osborne, L. L., \& McComish, J. F. (2006). Borderline personality disorder nursing interventions using dialectical behavioral therapy. Journal of Psychosocial Nursing, 44(6), 40-47.

Raven, C. (2009). Borderline personality disorder: Still a diagnosis of exclusion? Mental Health Today, 26-31.

Sanders, C., Rogers, A., Gardner, C., \& Kennedy, A. (2011). Managing 'difficult emotions' and bib family life: Exploring insights and social support within online self-management training. Chronic Illness, 7(2), 134-146.

Sansone, R. A., \& Sansone, L. A. (2010). Fatal attraction syndrome: Stalking behavior and borderline personality. Psychiatry, 7(5), 42-46.

Sansone, R. A., \& Sansone, L. A. (2011a). Gender patterns in borderline personality disorder. Innovative Clinical Neuroscience, 8(5), 16-20.

Sansone, R. A., \& Sansone, L. A. (2011b). Substance use disorder and borderline personality: Common bedfellows. Innovative Clinical Neuroscience, $8(9), 10-13$.

Sarkis, S. (2011). Borderline personality disorder: Big changes in the DSM-5. Psychology Today. Retrieved from http://www.psychologytoday.com/blog/ here-there-and-everywhere/201112/borderline-personality-disorder-bigchanges-in-the-dsm- 5 .

Seale, C., Charteris-Black, J., MacFarlane, A., \& McPherson, A. (2010). Interviews and internet forums: A comparison of two sources of qualitative data. Qualitative Health Research, 20(5), 595-606.

Stern, A. (1938). Psychoanalytic investigation of and therapy in the borderline group of neuroses. Psychoanalytic Quarterly, 7, 467-489.

Stoffers, J., Völlm, B., Rücker, G., Timmer, A., Huband, N., \& Lieb, K. (2010). Pharmacological interventions for borderline personality disorder. Cochrane Database of Systematic Review, 6, CD005653.

Stoffers, J., Völlm, B., Rücker, G., Timmer, A., Huband, N., \& Lieb, K. (2012). Psychological therapies for people with borderline personality disorder. Cochrane Database of Systematic Review, 8, CD005652.

Trull, T., Distel, M., \& Carpenter, R. (2010). DSM-5 borderline personality disorder: At the border between a dimensional and a categorical view. Current Psychiatry Report, 13(1), 43-49.

U.S. Department of Health and Human Services (DHHS), Healthy People 2020. (2012). Mental health and mental disorders. Retrieved from http://www. healthypeople.gov/2020/topicsobjectives2020/overview.aspx?topicId= 28http://www.borderlinepersonalitydisorder.com/understading-bpd/ a-bpd-brief/.

U.S. Department of Health and Human Services (DHHS), Healthy People 2020 (2013). Topics and objectives: Emerging issues in mental health and mental disorders. Retrieved from http://www.healthypeople.gov/2020/ topicsobjectives2020/overview.aspx?topicId $=28$.

Wehbe-Alamah, H., Kornblau, B., Haderer, J., \& Erickson, J. (2012). Silent no more! The lived experiences of women with lichen sclerosis. Journal of the American Academy of Nurse Practitioners, 8(24), 499-505. doi: $10.1111 /$ j.1745-7599.2012.00715.x

World Health Organization. (2010). People with mental disabilities cannot be forgotten. Medical News Today. Retrieved from http://www.medicalnewstoday.com/releases/201645.php. 